ДИАГНОСТИЧЕСКИЕ ПОДХОДЫ ПРИ КРИТИЧЕСКИХ СОСТОЯНИЯХ
DIAGNOSTIC APPROACHES FOR

CRITICAL CONDITIONS
Патогенез и клиническое

значение синдрома

гипердинамического

кровообращения при циррозе

печени. Обзор литературы

\author{
М.Л. Катин, М.Ю. Гурова, П.С. Прилуцкий, \\ А.М. Дзядзько, О.О. Руммо
}

ГУ «Минский научно-практический центр хирургии, трансплантологии и гематологии», Минск, Республика Беларусь

Peферат

Портальная гипертензия - основное осложнение цирроза печени, характеризующееся патологическим увеличением сопротивления в портальной системе кровотока печени. По мере развития портальной гипертензии формируются сосудистые коллатерали и прогрессирует артериальная вазодилатация. Гипердинамические проявления становятся более выражены в связи со снижением реакции на вазоконстрикторы и увеличение шунтирования вместе с автономной нейропатией. Комбинация печеночной недостаточности и портальной гипертензии ведет к развитию гипердинамического типа циркуляции частично за счет одновременной вазодилатации спланхнического и периферического артериального русла. Гипердинамический синдром является поздним проявлением портальной гипертензии при циррозе печени. Основными проявлениями гипердинамического синдрома являются высокий сердечный выброс, увеличенная частота сердечных сокращений и общий объем крови вкупе со сниженным общим системным сосудистым сопротивлением. Некоторые кардиоваскулярные изменения являются обратимыми после трансплантации печени и тем самым указывают на патофизиологическую значимость портальной гипертензии. В этом обзоре нами рассмотрена патофизиология и проявления гипердинамического синдрома, как хорошо известные и напрямую связанные с портальной гипертензией (варикозное расширение вен, асцит, печеночная энцефалопатия и гепаторенальный синдром), так и более редко встречающиеся и требующие дальнейшего изучения

\section{Pathogenesis and clinical significance of the hyperdynamic circulatory syndrome in liver cirrhosis. Review}

M.L. Katsin, M.Y. Hurava, P.S. Prylutski, A.M. Dzyadz'ko, O.O. Rummo

Minsk Scientific-Practical Center of Surgery, Transplantation and Hematology, Minsk, Republic of Belarus

\section{Abstract}

Portal hypertension is the major consequences of liver cirrhosis and is accompanied by pathologic increase in portal blood flow resistance. As portal hypertension develops that results in formation of vessel's collaterals and arterial vasodilatation. Hyperdynamic alternations become more significant due to hyporesponsiveness to vasoconstrictors and increased shunts formation with autonomic neuropathy. This combination of liver failure and portal hypertension leads to the hyperdynamic circulatory state partly owing to simultaneous vasodilatation of splanchnic and peripheral arterial vessels. So hyperdynamic circulatory syndrome is a late complication of portal hypertension due to liver cirrhosis. The main features of hyperdynamic circulatory syndrome are high cardiac output, increased heart rate and total blood volume coupled with decreased total systemic vascular resistance. Some of these cardiovascular changes are reversible after liver transplantation what show pathophysiological significance of portal hypertension. In this paper, we aimed to review pathophysiology and features of hyperdynamic syndrome that are well-known and directly related to portal hypertension (varices, ascites, hepatic encephalopathy and hepatorenal syndrome), while others are more rare and therefore further investigations are necessary (portopulmonary hypertension, cirrhotic cardiomyopathy).

Keywords: Liver Cirrhosis; Hypertension, Portal; Liver Failure; Liver Transplantation; Ascites; Hepatorenal Syndrome; Hepatic Encephalopathy; Vasodilation

$\quad$ For correspondence: Pavel S. Prylutski - MD, anesthesiologist and intensivist Department of Anesthesiology and Critical 
(портопульмональная гипертензия, цирротическая кардиомиопатия).

Ключевые слова: цирроз печени, портальная гипертензия, печеночная недостаточность, трансплантация печени, асцит, гепаторенальный синдром, печеночная энцефалопатия

\ Для корреспонденции: Прилуцкий Павел Сергеевич - врач анестезиолог-реаниматолог отделения анестезиологии и реанимации № 2 Минского научно-практического центра хирургии, трансплантологии и гематологии, Республика Беларусь; e-mail: pprilutski@gmail.com

¿ Дляцитирования: М.Л. Катин, М.Ю. Гурова, П.С. Прилуцкий, А.М. Дзядзько, О.О. Руммо. Патогенез и клиническое значение синдрома гипердинамического кровообращения при циррозе печени. Обзор литературы. Вестник интенсивной терапии им. А.И. Салтанова. 2021;1:123-133. DOI: 10.21320/1818-474X-2021-1-123-133

ए Поступила: 30.10 .2020

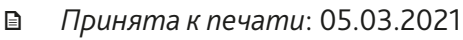

Care No 2, Minsk Scientific-Practical Center of Surgery, Transplantation and Hematology, Minsk, Republic of Belarus; e-mail: pprilutski@gmail.com

ए For citation: M.L. Katsin, M.Y. Hurava, P.S. Prylutski, A.M. Dzyadz'ko, O.O. Rummo. Pathogenesis and clinical significance of the hyperdynamic circulatory syndrome in liver cirrhosis. Review. Annals of Critical Care. 2021;1:123-133. DOI: 10.21320/1818-474X-2021-1-123-133

๘ Received: 30.10 .2020

目 Accepted: 05.03.2021

\section{Введение}

Портальная гипертензия (ПГ) - синдром, который служит основой тяжелых клинических проявлений цирроза печени (ЦП), таких как формирование варикозно расширенных вен пищевода или желудка и их разрыв, асцит и печеночная энцефалопатия. Основным механизмом повышения давления в воротной вене при ЦП является увеличение внутрипеченочной резистентности к портальному притоку. Морфологическим субстратом ПГ является отложение коллагена в ацинусе печени с сужением синусоидального просвета и, как следствие, уменьшение площади поперечного сечения печеночных синусоид. Помимо этого, увеличение внутрипеченочного портального сопротивления происходит за счет сдавления центролобулярных венул регенераторными узелками, гранулемами и развитием портального воспаления [1].

Помимо структурного компонента, в увеличении печеночной резистентности также участвует и потенциально обратимый, вазоактивный компонент [2]. При циррозе повышается сократительный тонус клеток гладких мышечных волокон и миофибробластов вокруг синусоид и венул печени [3]. Норадреналин, субстанция Р, тромбин, ангиотензин II, эндотелин и простаноиды могут повышать сократительный тонус миофибробластов и, следовательно, портальную резистентность
$[4,5]$. Однако основным источником динамического повышения внутрипеченочной портальной резистентности является эндотелиальная дисфункция. Снижение биологической доступности оксида азота (NO) в синусоидах и увеличение выработки простаноидов (продуктов метаболизма циклооксигеназы), таких как простагландин Н2 и тромбоксан А2, по-видимому, являются основными участниками эндотелиальной дисфункция при ЦП [6, 7].

Целью данного обзора является обобщение современных знаний о физиологии спланхнической вазодилатации и синдрома гипердинамического кровообращения (рис. 1), что является необходимым для профилактики и лечения ПГ и ее осложнений. Поиск публикаций для данного обзора проводился с использованием электронных ресурсов электронной библиотеки eLIBRARY. $\mathrm{ru}$, библиографической базы статей по медицинским наукам (MEDlars onLINE) Национальной медицинской библиотеки США (U.S. National Library of Medicine, NLM), базы данных Cochrane Reviews, a также China National Knowledge Infrastructure, WANGFANG DATA с 1966 по 2019 г. Глубина поиска составляла 35 лет. Из обнаруженных 662 источников для обзора литературы были отобраны 67, опубликованные преимущественно за последние 20 лет. 


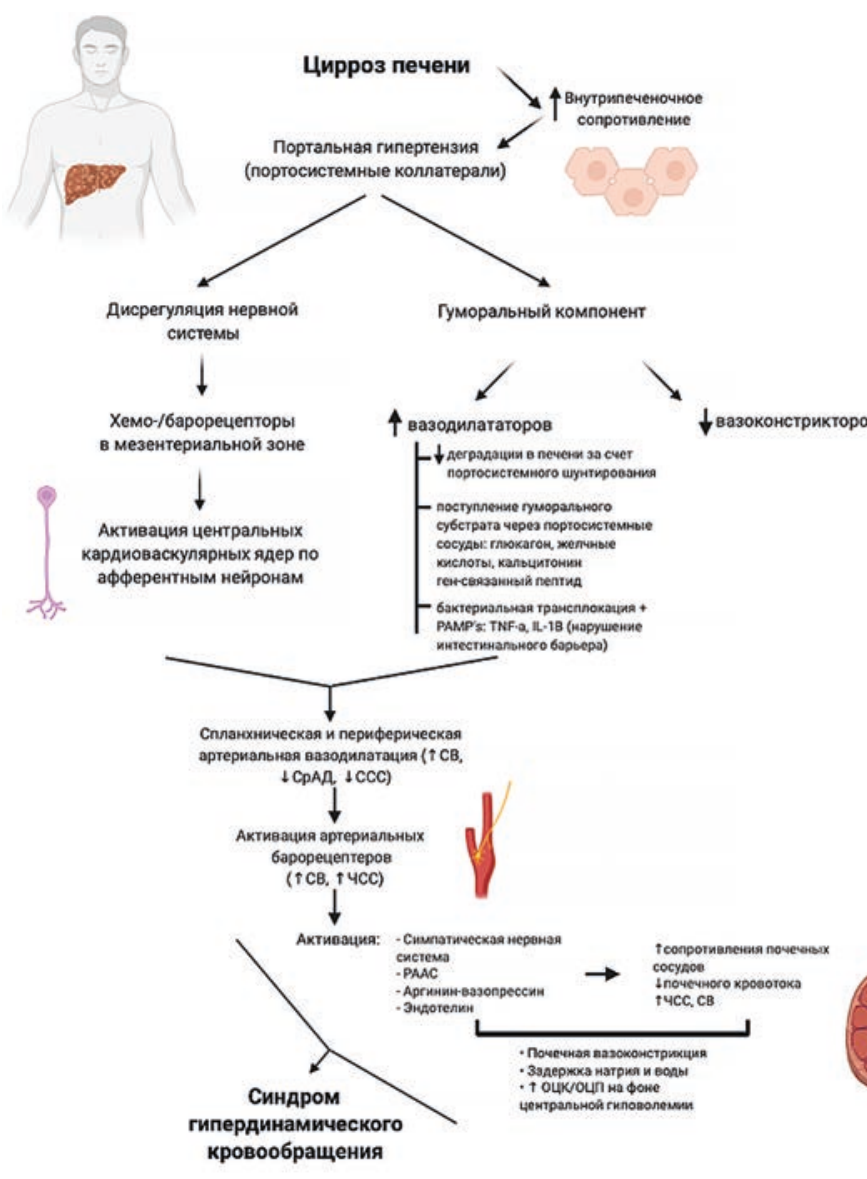

\section{Патофизиология портальной гипертензии}

\section{Увеличение спланхнического притока}

Из-за увеличения внутрипеченочной резистентности при ПГ можно было ожидать снижения портального кровотока. Однако несмотря на увеличение диаметра воротной вены и снижение в ней скорости потока крови, портальная гемодинамика при ЦП характеризуется развитием сети коллатералей с увеличением суммарного кровотока в системах воротной, селезеночной и брыжеечных вен [8].

Давление в воротной вене является результатом противодействия между объемной скоростью потока крови, поступающего в портальную систему, и сопротивлением оттоку на уровне цирротически измененной печени. Математическое выражение этой зависимости может быть представлено в виде формулы Ома (1.1):

$$
\mathbf{P}=\mathbf{Q} \times \mathbf{S}(1.1)
$$

где $P$ - изменение давления в сосуде;

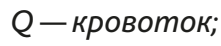

S-сопротивление потоку.

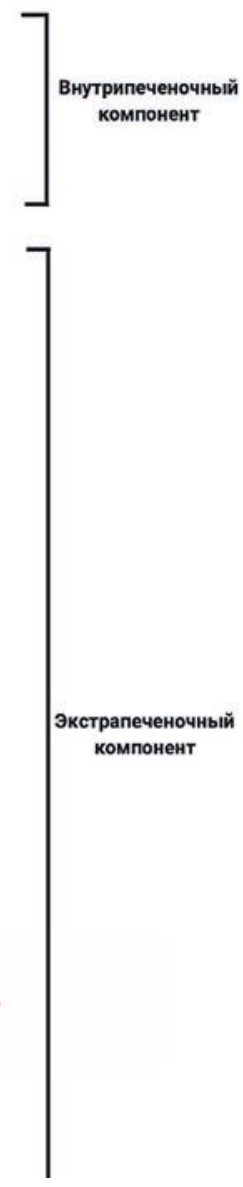

Рис. 1. Патофизиология синдрома гипердинамического кровообращения

Fig. 1. Pathophysiology of hyperdynamic circulation syndrome
Основной детерминантой ПГ при ЦП является увеличение сопротивления портальному потоку, в то время как увеличение притока играет второстепенную роль [9]. В печени с нормальной резистентностью при изменении портального кровотока давление в воротной вене не изменяется [10] из-за высокой степени податливости сосудов портальной системы. При увеличении сопротивления портальному потоку (вследствие ЦП) и снижении податливости сосудов системы воротной вены давление в воротной вене напрямую зависит от величины портального кровотока [11].

\section{Портосистемные коллатерали}

Механизмом, объясняющим поддержание высокой скорости объемного кровотока по системе воротной вены, является открытие портосистемных коллатералей, вызванное увеличением сопротивления оттоку от портальной системы. Открытие коллатерального кровообращения происходит посредством реперфузии и дилатации ранее существующих сосудов, а также вследствие генерации новых сосудов, как было показано в экспериментальных исследованиях, демонстрирующих роль ангиогенетических факторов, таких как фактор роста эндотелия сосудов (VEGF - vascular 
endothelial growth factor), в патогенезе развития коллатералей у крыс с индуцированной ПГ [12]. Портосистемные шунты ответственны за развитие желудочно-кишечного кровотечения, главным образом из-за разрыва варикозно расширенных вен пищевода или желудка. По ним же происходит попадание в системный кровоток ряда метаболитов, которые обычно удаляются печенью. Портосистемные шунты играют основную роль в патогенезе гипердинамического кровообращения, асцита и печеночной энцефалопатии [13].

\section{Спланхническая вазодилатация}

Увеличение спланхнического кровотока при ПГ вследствие ЦП вызвано вазодилатацией спланхнических артерий селезеночного и мезентериального бассейнов. В последние годы механизмы, ответственные за снижение резистентности мезентериальных артерий были тщательно изучены. В качестве возможных медиаторов были предложены многочисленные вещества и даже целые системы: глюкагон [13, 14], простациклин (PGI2), интестинальный вазоактивный пептид, гистамин, вещество Р, эстрогены, холецистокинин, аммиак, эндотоксины, аденозин, желчные кислоты, NO, пептид, связанный с геном а-кальцитонина, адреномедуллин, VEGF, монооксид углерода, эндогенные каннабиноиды. Эндотелиальные факторы также играют в этом процессе определенную роль $[13,15]$.

В настоящее время NO рассматривается в качестве основного фактора обусловливающего снижение мезентерального сопротивления при ЦП. NO имеет очень короткий период полувыведения (20-30 c), он свободно диффундирует через клеточную мембрану и действует главным образом за счет стимуляции гуанилатциклазы, выработки циклического гуанозинмонофосфата (цГМФ) с последующим расслаблением клеток гладкой мускулатуры. У пациентов с ПГ вследствие повышения активности эндотелиальной NO-синтетазы (eNOS Endothelial nitric oxide synthase) биодоступность NO значительно увеличена [16]. Этот факт получил подтверждение в ряде лабораторных экспериментов: у крыс с индуцированной ПГ наблюдалось повышение активности NOS даже в терминальных стадиях заболевания [15]. Данный феномен, по-видимому, обусловлен несколькими механизмами. Провоспалительные цитокины, VEGF и механические силы, такие как напряжение сдвига, индуцируют сигнальные каскады, основной целью которых является активация протеина теплового шока 90 (Hsp90, heat shock protein 90), который, в свою очередь, активирует еNOS [17]. Еще одним механизмом, увеличивающим содержание к крови фактора некроза опухоли, ко-фактора eNOS, и тетрагидробиоптерина является транслокация бактерий в брыжеечные лимфатические узлы из кишечника [18].

При декомпенсированном ЦП в эндотелии брыжеечных артерий активируется еще одна форма NO-синтета- зы - индуцированная синтетаза. Впрочем, ее активная роль в увеличении биодоступности NO в брыжеечном сосудистом русле пока не была продемонстрирована [19]. Помимо своего вазодилатирующего действия NO также является фактором ангиогенеза спланхнического циркуляторного русла, что продемонстрировано в ряде экспериментальных наблюдений [20].

Система NO/eNOS не является единственной, участвующей в вазодилатации брыжеечного сосудистого русла при ЦП. Это было доказано в эксперименте у лабораторных крыс с индуцированным ЦП, которым введение ингибиторов NOS лишь частично корректировало спланхническую вазодилатацию [15]. Тем самым было доказано вовлечение других вазоактивных систем в снижение брыжеечной сосудистой резистентности. У пациентов с ЦП также повышается циркуляторный уровень простагландина I2 (PGI2, prostaglandin I2), эндогенного вазодилататора, который, подобно NO, продуцируется клетками сосудистого эндотелия [21]. В экспериментальных условиях у лабораторных крыс с индуцированной ПГ было продемонстрировано усиление экспрессии циклооксигеназы-1. Ингибирование циклооксигеназы-1 индометацином снижало степень ПГ и улучшало гипердинамическое кровообращение [22].

Также в спланхнической дилатации при ЦП участвует конечный продукт катаболизма гема - оксид углерода (CO). СО, подобно NO, является активатором гуанилатциклазы, усиливая выработку цГМФ с последующим расслаблением клеток гладкой мускулатуры [23].

Эндогенные каннабиноиды - распространенные сигнальные молекулы липидной природы, которые реализуют свои центральные и периферические эффекты посредством воздействия на специфические рецепторы CB1 и СВ2. Экспериментальные данные свидетельствуют о том, что эндогенные каннабиноиды способствуют развитию спланхнической вазодилатации путем активации CB1-рецепторов в брыжеечной сосудистой сети. Влияние эндогенных каннабиноидов на брыжеечные сосуды, по-видимому, связано как с увеличением продукции NO, так и с неизученным NO-независимым механизмом [24].

Вазодилатация, наблюдаемая у пациентов с ПГ, также является следствием вегетативной дисфункции, вызываемой снижением реактивности к вазоконстрикторным системам, таким как симпатическая нервная система, вазопрессин, ангиотензин II и эндотелин-1.

Вегетативная дисфункция зачастую приписывается полинейропатии, связанной со злоупотреблением алкоголем, однако доказано участие в этом и иных механизмов [15]. Снижение регуляции или уменьшение сродства рецепторов к вазоконстрикторам может объяснить длительную системную и спланхническую вазодилатацию, которая происходит несмотря на компенсаторную активацию вазоконстрикторных систем [25]. 


\section{Селезеночная циркуляция и портальная гипертензия}

При ЦП увеличение кровотока по брыжеечной артерии не является единственным фактором, определяющим степень ПГ. Было отмечено, что у пациентов с ЦП и ПГ селезеночный кровоток увеличивается в большей степени, чем брыжеечный, обеспечивая до 60-70 \% портального притока [26]. Такое увеличение селезеночного кровотока при ЦП наблюдается у пациентов со спленомегалией. Помимо этого, существует взаимосвязь между размером селезенки и диаметром воротной вены, а также величиной селезеночного и портального кровотока [27].

Эти данные подтверждают, что спленомегалия и увеличение селезеночного кровотока при ЦП не являются пассивными явлениями, однако они также способствуют поддержанию ПГ путем перегрузки портальной системы объемом циркулирующей по ней крови [26].

\section{Патофизиология синдрома гипердинамической циркуляции}

Нарушения нормальной цитоархитектоники печени при циррозе приводят к развитию ряда структурных и сосудистых изменений. ПГ, а также артериальная вазодилатация в системном и спланхническом кровообращении при ЦП, часто ассоциированы с синдромом гипердинамической циркуляции (СГЦ). Основными проявлениями СГЦ являются увеличение сердечного выброса, частоты сердечных сокращений (ЧСС) и снижение общего периферического сосудистого сопротивления как ответ на снижение эффективного объема циркулирующей крови (ОЦК). Уменьшение эффективного ОЦК и активация барорецепторов правого предсердия, каротидных синусов и дуги аорты, в свою очередь, активируют симпатическую нервную систему и ренин-ангиотензин-альдостероновую систему, что приводит к задержке натрия и воды с возможным образованием асцита [15].

СГЦ также способствует развитию сердечно-сосудистых нарушений, включая диастолическую дисфункцию, снижение систолической реакции на стресс и ряд электрофизиологических нарушений, которые, проявляясь совместно, получили название цирротической кардиомиопатии [26].

СГЦ при ЦП характеризуется увеличением сердечного выброса и ЧСС, а также снижением общего периферического сопротивления сосудов, что проявляется снижением артериального давления [26]. Главной причиной этого является происходящие при ЦП системная и спланхническая вазодилатация, что в конечном итоге приводит к компенсаторным изменениям в сердечно-сосудистой системе в общем и региональных циркуляторных руслах отдельных органов.
Данный факт доказан в ряде экспериментальных исследований. Введение ингибиторов NOS лабораторным крысам с инсталлированным ЦП приводило к нормализации гемодинамических параметров [15], но только отчасти компенсировало спланхническую вазодилатацию [19]. У нейропептида Y, симпатического ко-трансмиттера норадреналина, обнаружены сходные эффекты в отношении редукции портального кровотока и улучшение гипердинамического состояния посредством спланхнической вазоконстрикции у лабораторных крыс с асцитом [28].

Коллатеральное кровообращение при ЦП способствует развитию СГЦ как напрямую, путем снижения периферического сопротивления потоку крови, так и косвенно, позволяя вазоактивным веществам из кишечника обойти печень и попасть в системный кровоток. Несмотря на снижение системного и висцерального сосудистого сопротивления при ЦП и ПГ, уменьшение резистентности кровотоку наблюдается не во всех региональных сосудистых руслах. Так, снижение кровотока при ПГ происходит в почках [29], головном мозге [30] и мышцах [31]. Чем быстрее прогрессирует печеночная недостаточность при ЦП, тем более выраженно уменьшается приток крови к этим органам [29].

СГЦ является патогенетической основой развития таких осложнений ЦП, как гепаторенальный синдром, гепатопульмональный синдром и тканевая гипоксия. Поскольку для функционирования печени и кишечника требуется около трети всего сердечного выброса, гипердинамическое кровообращение прямо или косвенно способствует развитию и прогрессированию еще двух серьезных осложнений ЦП - асцита и варикозного расширения вен пищевода.

Прямым следствием СГЦ являются и «классические» симптомы печеночной недостаточности: тахикардия, субцианотичная теплая кожа, системная артериальная гипотония.

Следующее важное проявление гипердинамического кровообращения - увеличение ОЦК [32]. Периферическая артериальная вазодилатация вызывает «депонирование» крови в сосудах спланхнической циркуляции, паренхиматозных органах и «емкостных» тканях (мышечная, жировая), вызывая тем самым снижение преднагрузки на сердце. Ответом на снижение преднагрузки является активация ряда нейрогуморальных систем (симпатоадреналовая, ренин-ангиотензин-альдостероновая, вазопрессин и пр.), что приводит к задержке натрия и жидкости, способствуя увеличению ОЦК [15].

\section{Цирротическая кардиомиопатия}

Несмотря на увеличение сердечного выброса, у пациентов с ЦП уменьшается амплитуда систолической и диастолической реакции миокарда желудочков на катехоламины и стресс. Обычно это сочетается с гипертрофией или дилатацией желудочков сердца, а также 
с рядом электрофизиологических нарушений (удлинение интервала QT) [28]. Изначально считалось, что причинной этому является манифестация латентной алкогольной кардиомиопатии, однако более поздние исследования показали схожую картину снижения сократимости сердца и при развитии неалкогольного ЦП, а также в экспериментальных моделях. Таким образом, в настоящее время изменения вентрикулярной сократимости при ЦП получило название «цирротической кардиомиопатии» (ЦКМП). В ее развитии, по-видимому, участвуют такие механизмы, как измененная $\beta$-адренэргическая передача сигналов, дисфункция мембраны кардиомиоцитов и избыточное поступление в кровоток при ЦП «прямых» кардиодепрессантов: NO, цитокины и эндоканнабиноиды [33]. Тем не менее, принимая во внимание ассоциацию с системной вазодилатацией, выраженная степень сердечной недостаточности все же не является характерным признаком этого осложнения.

В отсутствии специфических диагностических критериев точная частота развития ЦКМП остается неизвестной. Характерные проявления ЦКМП включают следующие: ослабленную систолическую или диастолическую реакцию на стрессорные стимулы, структурные или гистологические изменения камер сердца, электрофизиологические аномалии и повышение сывороточных маркеров, подтверждающих растяжение камер сердца [28].

Нарушение реактивности сердечно-сосудистой системы при циррозе, вероятно, вызвано комбинацией факторов, включающих физико-химические изменения мембран кардиомиоцитов, ослабление стимулирующих путей и усиление активности ингибирующих систем [33].

Во многих исследованиях уже было показано, что сократимость кардиомиоцитов в основном детерминирована стимуляцией $\beta$-адренергической системы. Эта система состоит из рецепторов, гуанин-нуклеотид-связывающего белка (G-протеин) и аденилатциклазы. Катехоламиновая стимуляция $\beta$-адренорептора вызывает ряд взаимодействий, приводящих к продукции вторичного мессенджера циклического аденозинмонофосфата. Циклический аденозинмонофосфат является первичным триггером, который вызывает изменения внутриклеточных потоков кальция и приводит к сокращению кардиомиоцита [34]. Функционирование этого механизма у пациентов с циррозом и в лабораторном эксперименте было оценено в различных исследованияx. Chen et al. продемонстрировали снижение плотности $\beta$-адренорецепторов у пациентов с ЦП и в лабораторных моделях [35]. Ma et al. показали, что $\beta$-адренорепторный сигнальный путь у пациентов с циррозом нарушается на различных уровнях регуляции: начиная от снижения плотности G-протеина на мембранах кардиомиоцитов и заканчивая нарушением активности самого фермента аденилатциклазы [36].
Было обнаружено, что у лабораторных мышей с ЦП ослабляется ответ на стимуляцию мускариновых рецепторов [37]. Стимуляция мускариновых рецепторов вызывает негативный инотропный эффект на сердечную мышцу, уравновешивая тем самым влияние $\beta$-адренергической системы. Таким образом, дисбаланс в регуляции $\beta$-адренергической системы и мускариновых рецепторов может вносить свой вклад в патогенез негативных инотропных эффектов на миокард.

Жидкотекучесть мембраны - термин, используемый для описания степени свободы перемещений липидных частиц в двойном липидном слое цитоплазматической мембраны [37]. Было продемонстрировано снижение жидкотекучих свойств цитоплазматических мембран кардиомиоцитов и других клеток организма у пациентов с ЦП [36]. Эти изменения оказывают глубокое воздействие на функционирование $\beta$-адренорецепторов, которое заключается в нарушении взаимодействия рецептор-лиганд, уменьшении плотности рецепторов и повреждении внутриклеточного пути передачи сигнала. Восстановление нормальных жидкотекучих свойств мембраны кардиомиоцитов в экспериментальных исследованиях приводило к выраженному улучшению функционирования $\beta$-адренорецепторов. Нарушение жидкотекучести мембраны также влияет на функционирование мембранных ионных каналов. Исследование продемонстрировало уменьшение функциональной активности двух типов калиевых каналов в кардиомиоцитах желудочков мышей с циррозом, которое потенциально могло бы объяснить пролонгацию интервала QТ на электрокардиограмме [38]. Помимо этого, при циррозе может уменьшаться и поступление кальция в клетку, вызывающее нарушение сократимости сердечной мышцы. Кальций поступает в клетку через мембранные кальциевые каналы, накапливаясь в ней и выделяясь во внеклеточное пространство посредством саркоплазматической сети. Дисфункция кальциевых каналов приводит к снижению сократимости кардиомиоцитов, что также было продемонстрировано в ряде лабораторных экспериментов [36, 38].

NO играет важную роль в регуляции системного и коронарного сосудистого тонуса, участвуя, таким образом, в патогенезе различных нарушений сердечно-сосудистой системы, включая ишемическую болезнь сердца [39]. Неселективная блокада NOS N-омега-монометил-L-аргинином усиливает сократительную реакцию кардиомиоцитов желудочков мышей на изопротеренол без каких-либо эффектов на общую сократимость, подтверждая тем самым ингибиторный әффект NO на сократимость сердца. Аналогично в другом исследовании ингибирование синтеза NO посредством $\mathrm{N}$-омега-монометил-L-аргинином восстанавливало сократительную функцию желудочков у мышей с циррозом без выраженного эффекта на животных из контрольной группы [40]. 
СО является известным вазодилататором, который также оказывает негативное влияние на сократимость сердца посредством взаимодействия с цГМФ [23]. СО стимулирует гуанилатциклазу, вызывая продукцию цГМФ, который, в свою очередь, активизирует фосфориляцию протеинкиназы G и ингибирует поступление кальция в цитозоль кардиомиоцита. Liu et al. исследовали роль СО в патогенезе ЦКМП. Они показали, что транскрипция матричной рибонуклеиновой кислотой и экспрессия протеина НО-1 в желудочках животных с циррозом значительно увеличиваются в сравнении с контрольной группой животных. Также ими продемонстрировано, что подавление гемоксигеназы значительно уменьшает прирост содержания цГМФ и восстанавливает сниженную сократимость изолятов сосочковых мышц лабораторных животных с циррозом без эффекта на изоляты мышц из контрольной группы [41]. Основываясь на этих находках, Liu et al. подтвердили, что активация пути $\mathrm{HO} / \mathrm{CO}$ также вовлечена в патогенез ЦКМП.

Положительная регуляция каннабиноидного сигнального пути также имеет место при хронических заболеваниях печени [24]. Эндогенные каннабиноиды оказывают негативный инотропный эффект в лабораторных моделях посредством их взаимодействия с ингибирующими рецепторами, связанными с G-протеином CB1 и СB2, приводя к подавлению активности аденилатциклазы и поступления кальция в цитозоль кардиомиоцита. Gaskari et al. показали, что нарушенная сократимость изолятов сосочковой мышцы левого желудочка восстанавливается после преинкубации ее с антагонистом СB1 [41].

Пациенты с ЦКМП в течение длительного времени могут оставаться бессимптомными из-за снижения постнагрузки на сердце, вызванного системной вазодилатацией, что маскирует клинические проявления легкой или умеренной дисфункции сердца. Сердечная недостаточность у пациентов с ЦП зачастую манифестирует клинически после проведения таких вмешательств, как парацентез большого объема асцита, трансъюгулярное внутрипеченочное портосистемное шунтирование (TIPS - Transjugular Intrahepatic Portosystemic Shunt), трансплантация печени или агрессивная трансфузионная терапия для компенсации кровопотери из варикозно расширенных вен пищевода [42].

Систолическая функция левого желудочка при ее оценке в состоянии покоя по фракции выброса левого желудочка обычно является нормальной (55-60 \%). Тем не менее во время физической нагрузки, стресс-тесте и прочих состояниях, при которых повышается производительность левого желудочка, у пациентов с ЦП в сравнении с контрольной группой наблюдается менее выраженное увеличение фракции выброса левого желудочка [43]. Подобное нарушение сократительной способности миокарда является результатом снижения функционального резерва миокарда. Также у пациен- тов с ЦП может наблюдаться «притупление» реакции миокарда на катехоламины в виде менее выраженного в сравнении с контрольной группой увеличения ЧСС $[42,43]$.

Несмотря на снижение постнагрузки на сердце, приблизительно у 30 \% пациентов с ЦП развивается гипертрофия левого желудочка. Эта гипертрофическая реакция миокарда может быть связана с гемодинамической перегрузкой желудочков (механическим стрессом) или активацией нейрогуморальных путей с последующим ремоделированием миокарда и развитием фиброза. Необходимо отметить, что после выполнения ортотопической трансплантации печени (ОТП) происходит быстрая регрессия гипертрофии левого желудочка [44].

Гипертрофия миокарда, развивающаяся при ЦП, уменьшает растяжимость левого желудочка во время диастолы. Следовательно, относительно небольшое увеличение внутрисосудистого объема может приводить к значительному повышению конечно-диастолического давления. Диастолическая дисфункция левого желудочка может быть самым ранним проявлением сердечной недостаточности у пациентов с ЦКМП, что было обнаружено у 56 \% пациентов с применением ультразвуковой тканевой допплерографии [42]. Диастолическая дисфункция связана с плохой переносимостью больших сдвигов внутрисосудистой жидкости, происходящих при ОТП [45].

Удлинение интервала QТ - широко известный ЭКГ-феномен у пациентов с ЦП и может быть следствием изменения жидкотекучести плазматической мембраны кардиомиоцитов и ухудшения ионного транспорта через калиевые каналы $[36,38]$. Считается, что это может быть потенциальной причиной желудочковых аритмий и внезапной сердечной смерти [45]. Выраженность удлинения интервала QT имеет четкую взаимосвязь с тяжестью печеночной недостаточности при ЦП и нормализуется после выполнения ОТП [46]. У пациентов с ЦП также часто имеют место аномальные хронотропные ответы на физиологические и фармакологические стимулы. Несмотря на наличие у многих пациентов с тяжелой печеночной недостаточностью тахикардии, все же большинство их них не способны значительно увеличить ЧСС при определенных физиологических состояниях (например, при сепсисе, кровопотере), что может ухудшить способность сердца поддерживать адекватный метаболическим запросам уровень СВ [42, 43].

\section{Гепаторенальный синдром}

Гепаторенальный синдром (ГРС) является уникальной формой острой почечной недостаточности, вызванной выраженной вазоконстрикцией почечных сосудов у пациентов с прогрессирующим ЦП.

ГРС может возникать спонтанно или быть вызван провоцирующим фактором (> 70 \% случаев ГРС 1-го типа) [47]. Триггерными событиями для развития 
ГРС могут быть бактериальная инфекция, высокообъемный парацентез, желудочно-кишечное кровотечение, алкогольный гепатит, а также развитие ЦКМП и уменьшение сердечного выброса [48].

Патофизиология ГРС полностью не определена, однако она включает прогрессирование относительной гиповолемии за счет спланхнической вазодилатации и активацию чрезмерной почечной вазоконстрикции, приводящую к нарушенному почечному кровотоку, задержке натрия и жидкости $[47,49]$.

Ключевым в постановке диагноза ГРС является исключение остальных возможных причин почечной недостаточности. Быстрая идентификация ГРС уменьшает задержку терапии и ожидаемо позитивно влияет на исход [50].

ГРС 1-го типа - острая и быстро прогрессирующая форма почечной недостаточности, проявляющаяся увеличением сывороточного креатинина > 221 ммоль/л с прогнозируемой летальностью в нескольких недель при отсутствии возможности трансплантации печени [51]. ГРС 2-го типа протекает менее агрессивно, характеризуется увеличением сывороточного креатинина $>133$ ммоль/л и обычно связан с рефрактерным асцитом [52].

ГРС связан с значительной морбидностью и летальностью, определяющей негативный прогноз, часто измеряемый неделями [53]. Лучшим выбором в плане долгосрочной выживаемости у таких пациентов является трансплантация печени, а терапией первой линии вазоконстрикторы, хотя их реальный эффект скорее заключается в увеличении кратковременной выживаемости и возможности быть мостом к трансплантации печени [54]. Совместное назначение аналога вазопрессина, терлипрессина, вместе с альбумином является терапией первой линии при ГРС 1-го и 2-го типов для противодействия спланхнической вазодилатации [51]. Может быть рассмотрено применение других вазоконстрикторов, $а$-адренергических агонистов, однако на данный момент недостаточно убедительных данных в пользу их применения [55].

TIPS также является возможной терапевтической опцией, улучшающей почечную функцию при ГРС 1-го и 2-го типов, но его применимость ограничена тяжелой печеночной недостаточностью [56]. Фактически TIPS не улучшает значительно выживаемость у пациентов с резко сниженной функцией печени (Child B и C), однако, несмотря на это, некоторые работы показывают положительный эффект TIPS у пациентов с ГРС 2-го типа и 10-12 баллами по Чайлду-Пью, ожидающих трансплантацию печени [51, 57].

\section{Гепатопульмонарный синдром}

Гепатопульмонарный синдром (ГПС) встречается у 5-32 \% пациентов с ЦП и определяется наличием заболевания печени и/или ПГ и внутрилегочной вазоди- латацией, что ведет к нарушению альвеоло-артериального градиента кислорода $\left(\mathrm{PaO}_{2}<80\right.$ мм рт. ст. и $\mathrm{A}-\mathrm{aPO}_{2}$ $>15$ мм рт. ст. или $>20$ мм рт. ст. для пациентов старше 64 лет) [58].

Патофизиология ГПС на сегодняшний день до конца не определена. Принято считать оксид азота медиатором внутрилегочной вазодилатации у пациентов с ЦП и ГПС, т. к. у них выше уровни выдыхаемого NO в сравнении с пациентами без ГПС, а также в связи с нормализацией уровня выдыхаемого NO после трансплантации печени [59]. У пациентов с ГПС дилатированы капилляры и прекапилляры до 100 мм в диаметре, увеличено число данных дилатированных сосудов и нарушены механизмы их гипоксической вазоконстрикции [60]. Как результат, смешанная венозная кровь быстрее проходит к легочным венам, тем самым увеличивая кровоток в условиях неизмененной вентиляции, что ведет к нарушению вентиляционно-перфузионного соотношения. С прогрессированием ГПС эффективная оксигенация крови в центре дилатированных альвеолярных капилляров становится невозможна при обычной концентрации кислорода, и требуется увеличение фракции вдыхаемого кислорода, что определяет ГПС как физиологический, а не анатомический (справа налево) шунт. Тем не менее попытки фармакологически повлиять на продукцию NO и внутрилегочную вазодилатацию показали противоречивый результат [61]. Также с ГПС ассоциировано наличие полиморфизма единичных нуклеотидов, регулирующих ангиогенез и ремоделирование легочных сосудов [62].

Проявления ГПС у пациентов с ЦП неспецифичны и чаще всего представляют собой диспноэ (до 70 \% пациентов) [63]. Заподозрить ГПС при физикальном осмотре позволяет наличие паукообразных ангиом, цианоза и выраженной гипоксемии. Так как изменение положения тела может влиять на распределение легочного кровотока за счет увеличения перфузии дилатированных сосудов в базальных отделах легких, то пациенты могут отмечать ухудшение дыхания в положении сидя/стоя (ортодеоксия и платипноэ) и, напротив, улучшение в положении лежа. Диагностическим критерием ГПС является нарушение оксигенации в условиях внутрилегочной вазодилатации и сопутствующего почечного заболевания и ПГ [64]. Инструментальная диагностика включает контрастную эхокардиографию и легочное перфузионное сканирование с меченными технецием макроагрегатами альбумина для определения внутрилегочной вазодилатации [65]. На данный момент нет эффективной фармакологической терапии ГПС, а единственной терапией выбора является трансплантация печени (полное восстановление газообмена в более чем 80 \% случаев) [66]. Пациенты с ЦП и ГПС с $\mathrm{PaO}_{2}<60$ мм рт. ст. должны быть ургентно поставлены в лист трансплантации печени независимо от MELD [67]. 


\section{Заключение}

Увеличение давления в воротной вене при ПГ, являющееся причиной таких осложнений ЦП, как желудочно-кишечные кровотечения, асцит, печеночная энцефалопатия, ГРС и спонтанный бактериальный перитонит, происходит не только за счет повышения внутрипеченочной резистентности к портальному притоку, но и в результате увеличения спланхнического притока крови в портальную сосудистую систему. Усиление спланхнического кровотока обусловлено вазодилатацией спланхнических сосудов, как селезеночного, так и мезентериального кровообращения, и развитием коллатеральной циркуляции. Повышение в спланхническом кровотоке продукции NO рассматривается в качестве основной причины вазодилатации. Тем не менее другие молекулы, такие как PGI2, ФPЭС, СО и эндоканнабиноиды, также играют роль в этом процессе. Спланхническая вазодилатация характеризуется повышением сердечного выброса и ЧСС, а также снижением системного периферического сосудистого сопротивления и артериального давления. Синдром гиперкинетической циркуляции проявляется мультиорганными нарушениями, клиническая манифестация которых при ЦП характеризуется развитием асцита, варикозного расширения вен пищевода, ГРС, ЦКМП, ГПС и др. Понимание патофизиологии вазодилатации и синдрома гипердинамического кровообращения имеет важное значения для профилактики и лечения осложнений ПГ.

Конфликт интересов. Авторы заявляют об отсутствии конфликта интересов.

Вклад авторов. Катин М.Л., Гурова М.Ю., Прилуцкий П.С., Дзядзько А.М., Руммо О.О. - разработка концепции статьи, получение и анализ фактических данных, написание и редактирование текста статьи, проверка и утверждение текста статьи.

\section{ORCID авторов}

Катин М.Л. - 0000-0001-8129-1249

Гурова М.Ю. - 0000-0003-4923-7204

Прилуцкий П.С. - 0000-0002-5274-2714

Дзядзько А.М. - 0000-0003-1965-1850

Руммо О.О. - 0000-0001-7023-4767

\section{Литература/References}

[1] Nagula S., et al. Histological-hemodynamic correlation in cirrhosis-a histological classification of the severity of cirrhosis. J. of Hepatol. 2006, 44(1): 111-117. DOI: 10.1016/j.jhep.2005.07.036

[2] Zhou W.C., Zhang Q.B., Qiao L. Pathogenesis of liver cirrhosis. World J. of Gastroenterol. 2014, 20(23): 7312-7324. DOI: $10.3748 /$ wjg.v20.i23.7312

[3] Garbuzenko D.V., Arefyev N.O., Kazachkov E.L. Antiangiogenic therapy for portal hypertension in liver cirrhosis: current progress and perspectives. World J. of Gastroenterol. 2018, 24(33): 37383748. DOI: 10.3748/wjg.v24.i33.3738

[4] Grancea-lancu M. Involvement of vasoactive substances in hemodynamics disturbances in cirrhosis. J. of Med. and Life. 2014, 7(3): 40-43. PMCID: PMC4391417

[5] Graupera M., et al. Cyclooxygenase-derived products modulate the increased intrahepatic resistance of cirrhotic rat livers. Hepatology. 2003, 37(1): 172-181. DOI: 10.1053/jhep.2003.50004

[6] Di Pascoli M., et al. Molecular mechanisms leading to splanchnic vasodilation in liver cirrhosis. J. of Vasc. Res. 2017, 54(2): 92-99. DOI: $10.1159 / 000462974$

[7] Gracia-Sancho J., et al. Enhanced vasoconstrictor prostanoid production by sinusoidal endothelial cells increases portal perfusion pressure in cirrhotic rat livers. J. of Hepatol. 2007, 47(2): 220-227. DOI: 10.1016/j.jhep.2007.03.014

[8] Bandali M.F., et al. Portal hypertension: imaging of portosystemic collateral pathways and associated image-guided therapy. World J. of Gastroenterol. 2017, 23(10): 1735-1746. DOI: $10.3748 /$ wjg.v23.i10.1735
[9] Prin M., Bakker J., Wagener G. Hepatosplanchnic circulation in cirrhosis and sepsis. World J. of Gastroenterol. 2015, 21(9): 25822592. DOI: $10.3748 /$ wjg.v21.i9.2582

[10] Nakagawa A., et al. Usefulness of portal vein pressure for predicting the effects of tolvaptan in cirrhotic patients. World J. of Gastroenterol. 2016; 22(21): 5104-1513. DOI: $10.3748 /$ wjg.v22.i21.5104

[11] Sastre E., et al. Decompensated liver cirrhosis and neural regulation of mesenteric vascular tone in rats: role of sympathetic, nitrergic and sensory innervations. Sci. Rep. 2016, 6. DOI: 10.1038/srep31076

[12] Gana J.C., Serrano A., Ling S.C. Angiogenesis and portal-systemic collaterals in portal hypertension. Ann. of Hepatol. 2016, 15(3): 303-313. DOI: 10.5604/16652681.1198799

[13] Gatta A., Bolognesi M., Merkel C. Vasoactive factors and hemodynamic mechanisms in the pathophysiology of portal hypertension in cirrhosis. Mol. Aspects of Med. 2008, 29(1-2): 119-129. DOI: 10.1016/j.mam.2007.09.006

[14] McConnell M., Iwakiri Y. Biology of portal hypertension. Hepatol. Int. 2018, 12(1): 11-23. DOI: 10.1007/s12072-017-9826-x

[15] Bolognesi M., et al. Splanchnic vasodilation and hyperdynamic circulatory syndrome in cirrhosis. World J. of Gastroenterol. 2014, 20(10): 2555-2563. DOI: 10.3748/wjg.v20.i10.2555

[16] Schwabl P., et al. The FXR agonist PX20606 ameliorates portal hypertension by targeting vascular remodelling and sinusoidal dysfunction. J. of Hepatol. 2017, 66(4): 724-733. DOI: 10.1016/j.jhep.2016.12.005 
[17] Dimmeler S., et al. Activation of nitric oxide synthase in endothelial cells by Akt-dependent phosphorylation. Nature. 1999; 399(6736): 601-605. DOI: $10.1038 / 21224$

[18] Wiest R., et al. Bacterial translocation in cirrhotic rats stimulates eNOS-derived NO production and impairs mesenteric vascular contractility. The J. of Clin. Invest. 1999; 104(9): 1223-1233. DOI: $10.1172 / \mathrm{JCl} 7458$

[19] Angeli P., et al. The role of nitric oxide in the pathogenesis of systemic and splanchnic vasodilation in cirrhotic rats before and after the onset of ascites. Liver Int. 2005; 25(2): 429-437. DOI: 10.1111/j.1478-3231.2005.01092.x

[20] Lee P.C., et al. Concomitant inhibition of oxidative stress and angiogenesis by chronic hydrogen-rich saline and $\mathrm{N}$-acetylcysteine treatments improves systemic, splanchnic and hepatic hemodynamics of cirrhotic rats. Hepatol. Res. 2015, 45(5): 578588. DOI: 10.1111/hepr.12379

[21] Sacerdoti D., et al. Arachidonic acid metabolites and endothelial dysfunction of portal hypertension. Prostaglandins \& Other Lipid Mediat. 2015; 120: 80-90. DOI: 10.1016/j.prostaglandins.2015.05.008

[22] Tu C.T., et al. Antifibrotic activity of rofecoxib in vivo is associated with reduced portal hypertension in rats with carbon tetrachlorideinduced liver injury. J. of Gastroenterol. and Hepatol. 2007; 22(6): 877-884. DOI: 10.1111/j.1440-1746.2007.04867.x

[23] Bolognesi M., et al. Carbon monoxide-mediated activation of largeconductance calcium-activated potassium channels contributes to mesenteric vasodilatation in cirrhotic rats. The J. of Pharmacol. and Exp. Ther. 2007; 321(1): 187-194. DOI: 10.1124/jpet.106.116665

[24] Dai E., et al. Hepatic expression of cannabinoid receptors CB1 and CB2 correlate with fibrogenesis in patients with chronic hepatitis $B$. Int J Infect Dis. 2017; 59: 124-130. DOI: 10.1016/j.ijid.2017.03.008

[25] Alvarado E., et al. The relationship of hyperdynamic circulation and cardiodynamic states in cirrhosis. J. of Hepatol. 2018; 69(3): 746-747. DOI: 10.1016/j.jhep.2018.04.026

[26] Hennenberg M., et al. Mechanisms of extrahepatic vasodilation in portal hypertension. Gut. 2008; 57(9): 1300-1314. DOI: 10.1136/gut.2007.144584

[27] Wei W., et al. Wall shear stress in portal vein of cirrhotic patients with portal hypertension. World J. of Gastroenterol. 2017; 23(18): 3279-3286. DOI: 10.3748/wjg.v23.i18.3279

[28] Hollenberg S.M., Waldman B. The circulatory system in liver disease. Crit. Care Clin. 2016; 32(3): 331-342. DOI: 10.1016/j.ccc.2016.02.004

[29] Mindikoglu A.L., Pappa S.C. New Developments in Hepatorenal Syndrome. Clin. Gastroenterol. and Hepatol. 2018; 16(2): 162-177. e1. DOI: 10.1016/j.cgh.2017.05.041

[30] Iwasa M., et al. Decrease of regional cerebral blood flow in liver cirrhosis. Eur. J. of Gastroenterol. \& Hepatol. 2000; 12(9): 10011006. DOI: 10.1097/00042737-200012090-00006

[31] Tripathi D.M., et al. Metformin reduces hepatic resistance and portal pressure in cirrhotic rats. Am. J. of Physiol. and Gastrointest. Liver Physiol. 2015; 309(5): G301-G309. DOI: 10.1152/ajpgi.00010.2015

[32] Weiss E., Paugam-Burtz C., Jaber J. Shock etiologies and fluid management in liver failure. Semin. in Respir. and Crit. Care Med. 2018; 39(5): 538-545. DOI: 10.1055/s-0038-1672139
[33] Lee Y.B., Lee J.H. Cirrhotic cardiomyopathy: an independent prognostic factor for cirrhotic patients. Clin. and Mol. Hepatol. 2018; 24(4): 372-373. DOI: 10.3350/cmh.2018.0098

[34] Wachter S.B., Gilbert E.M. Beta-adrenergic receptors, from their discovery and characterization through their manipulation to beneficial clinical application. Cardiology. 2012; 122(2): 104-112. DOI: 10.1159/000339271

[35] Chen W., et al. Desensitization of G-protein-coupled receptors induces vascular hypocontractility in response to norepinephrine in the mesenteric arteries of cirrhotic patients and rats. Hepatobiliary \& Pancreat. Dis. Int. 2013; 12(3); 295-304. DOI: 10.1016/s1499-3872(13)60047-8

[36] Ma Z., Lee S.S., Meddings J.B. Effects of altered cardiac membrane fluidity on beta-adrenergic receptor signalling in rats with cirrhotic cardiomyopathy. J. of Hepatol. 1997; 26(4): 904-912. DOI: 10.1016/s0168-8278(97)80259-0

[37] Scheinpflug K., Krylova O., Strahl H. Measurement of cell membrane fluidity by laurdan gp: fluorescence spectroscopy and microscopy. Methods in Mol. Biol. 2017; 1520: 159-174. DOI: 10.1007/978-1-4939-6634-9_10

[38] Ward C.A., et al. Potassium currents in atrial and ventricular myocytes from a rat model of cirrhosis. Am J. of Physiol. 1997; 273(2): G537-G544. DOI: 10.1152/ajpgi.1997.273.2.G537

[39] Liu H., Gaskari S.A., Lee S.S. Cardiac and vascular changes in cirrhosis: pathogenic mechanisms. World J. of Gastroenterol. 2006; 12(6): 837-842. DOI: 10.3748/wjg.v12.i6.837

[40] Liu H., Ma Z., Lee S.S. Contribution of nitric oxide to the pathogenesis of cirrhotic cardiomyopathy in bile ductligated rats. Gastroenterology. 2000; 118(5): 937-944. DOI: 10.1016/s0016-5085(00)70180-6

[41] Gaskari S.A., et al. Role of endocannabinoids in the pathogenesis of cirrhotic cardiomyopathy in bile duct-ligated rats. Br. J. of Pharmacol. 2005; 146(3): 315-323. DOI: 10.1038/sj.bjp.0706331

[42] Licata A., et al. Clinical implications of the hyperdynamic syndrome in cirrhosis. Eur. J. of Intern. Med. 2014; 25(9): 795-802. DOI: 10.1016/j.ejim.2014.09.004

[43] Fede G., et al. Cardiovascular dysfunction in patients with liver cirrhosis. Ann. of Gastroenterol. 2015; 28(1): 31-40. PMCID: PMC4290002

[44] Batra S., et al. The impact of left ventricular hypertrophy on survival in candidates for liver transplantation. Liver Transpl. 2014, 20(6): 705-712. DOI: 10.1002/lt.23875

[45] Costa M.G., Chiarandini P., Della Rocca G. Hemodynamics during liver transplantation. Transplant. Proc. 2007; 39(6): 1871-1873. DOI: 10.1016/j.transproceed.2008.03.070

[46] Bernardi M., et al. QT interval prolongation in liver cirrhosis: innocent bystander or serious threat? Expert Rev. of Gastroenterol. \& Hepatol. 2012, 6(1): 57-66. DOI: 10.1586/egh.11.86

[47] Wadei H.M., Mai M.L., Ashan N. Hepatorenal syndrome: pathophysiology and management. Clin J Am Soc Nephrol. 2006; 1: 1066-1079. DOI: 10.2215/CJN.01340406

[48] Zhang D.Q., et al. Risk factors of hepatorenal syndrome in patients with acute on chronic liver failure. Zhonghua Gan Zang Bing Za Zhi. 2013; 21: 743-746. DOI: 10.3760/cma.j.issn.1007-3418.2013.10.006 
[49] Bosch J., et al. The clinical use of HVPG measurements in chronic liver disease. Nat Rev Gastroenterol Hepatol. 2009; 6(10): 573582. DOI: $10.1038 /$ nrgastro.2009.149

[50] Angeli P., et al. Diagnosis and management of acute kidney injury in patients with cirrhosis: revised consensus recommendations of the International Club of Ascites. J Hepatology. 2015; 62: 968974. DOI: 10.1016/j.jhep.2014.12.029

[51] Angeli P., et al. European Association for the Study of the Liver. EASL clinical practice guidelines on the management of ascites, spontaneous bacterial peritonitis, in hepatorenal syndrome in cirrhosis. I Hepatol. 2010; 53(3): 397-417. DOI: 10.1016/j.jhep.2010.05.004

[52] Salerno F., et al. Diagnosis, prevention and treatment of hepatorenal syndrome in cirrhosis. Gut. 2007; 56: 1310-1318. DOI: $10.1136 /$ gut.2006.107789

[53] Ginès $P$., et al. Hepatorenal syndrome. Lancet. 2003; 362: 1819 1827. DOI: $10.1038 / \mathrm{s} 41572-018-0022-7$

[54] Licata A., et al. Clinical course and prognostic factors of hepatorenal syndrome: A retrospective single-center cohort study. World J Hepatol. 2013; 5(12): 685-691. DOI: 10.4254/wjh.v5.i12.685

[55] Martin-Llahi M., et al. Terlipressin and albumin vs albumin in patients with cirrhosis and hepatorenal syndrome: a randomized study. Gastroenterology. 2008; 134: 1352-1359. DOI: 10.1053/j.gastro.2008.02.024

[56] Ripoll C., et al. Hepatic venous gradient predicts clinical decompensation in patients with compensated cirrhosis. Gastroenterology. 2007; 133: 481-488. DOI: 10.1053/j.gastro.2007.05.024

[57] Testino G., et al. Type-2 hepatorenal syndrome and refractory ascites: role of transjugular intrahepatic portosystemic stentshunt in eighteen patients with advanced cirrhosis awaiting orthotopic liver transplantation. Hepatogastroenterology. 2003; 50(54): 1753-1755. PMID: 14696397
[58] Rodriguez-Roisin R., et al. Hepatopulmonary syndrome - a liverinduced lung vascular disorder. N Engl J Med. 2008; 358: 23782387. DOI: 10.1056/NEJMra0707185

[59] Cremona G., et al. Elevated exhaled nitric oxide in patients with hepatopulmonary syndrome. Eur Respir J. 1995; 8: 1883-1885. DOI: $10.1183 / 09031936.95 .08111883$

[60] Berthelot P., et al. Arterial changes in the lungs in cirrhosis of the liver-lung spider nevi. N Engl J Med. 1966; 274: 291-298. DOI: 10.1056/NEJM196602102740601

[61] Fallon M.B. Methylene blue and cirrhosis: pathophysiologic insights, therapeutic dilemmas. Ann Intern Med. 2000; 133: 738740. DOI: 10.7326/0003-4819-133-9-200011070-00016

[62] Roberts K.E., et al. Genetic risk factors for hepatopulmonary syndrome in patients with advanced liver disease. Gastroenterology. 2010; 139(130): 9.e24. DOI: 10.1053/j.gastro.2010.03.044

[63] Sood G. et al. Utility of dyspnea-fatigue index for screening liver transplant candidates for hepatopulmonary syndrome. Hepatology. 1998; 28: 2319.

[64] Rodriguez-Roisin R., et al. Pulmonary-hepatic vascular disorders [PHD]. Eur Respir J. 2004; 24: 861-880. DOI: 10.1183/09031936.04.00010904

[65] Abrams G.A., et al. Diagnostic utility of contrast echocardiography and lung perfusion scan in patients with hepatopulmonary syndrome. Gastroenterology. 1995; 109: 1283-1288. DOI: 10.1016/0016-5085(95)90589-8

[66] Goldberg D.S., et al. Impact of the hepatopulmonary syndrome MELD exception policy on outcomes of patients after liver transplantation: an analysis of the UNOS database. Gastroenterology. 2014; 146(5): 1256-1265. DOI: 10.1053/j.gastro.2014.01.005

[67] Fallon M.B., et al. Model for end-stage liver disease [MELD] exception for hepatopulmonary syndrome. Liver Transpl. 2006; 12: 105-107. DOI: 10.1002/lt.20971 